\title{
Frontières
}

\section{De l'éternité@l’internité}

\section{Joseph J. Lévy}

Volume 19, numéro 1, automne 2006

Enjeux politiques et mort

URI : https://id.erudit.org/iderudit/016652ar

DOI : https://doi.org/10.7202/016652ar

Aller au sommaire du numéro

Éditeur(s)

Université du Québec à Montréal

ISSN

1180-3479 (imprimé)

1916-0976 (numérique)

Découvrir la revue

Citer ce document

Lévy, J. J. (2006). De l'éternité@l'internité. Frontières, 19(1), 114-114.

https://doi.org/10.7202/016652ar

Ce document est protégé par la loi sur le droit d'auteur. L'utilisation des services d'Érudit (y compris la reproduction) est assujettie à sa politique d'utilisation que vous pouvez consulter en ligne.

https://apropos.erudit.org/fr/usagers/politique-dutilisation/
Cet article est diffusé et préservé par Érudit.

Érudit est un consortium interuniversitaire sans but lucratif composé de l’Université de Montréal, l'Université Laval et l'Université du Québec à Montréal. Il a pour mission la promotion et la valorisation de la recherche. https://www.erudit.org/fr/ 
Joseph J. Lévy

De nombreux sites peuvent directement ou indirectement toucher la question des rapports entre politique et mort. L'abondance des ressources dans ce domaine rend difficile la sélection. Nous présentons ici quelques sites à titre indicatif.

\section{DROIT HUMANITAIRE INTERNATIONAL}

\section{http://www.law.case.edu/war-crimes-research-}

portal/links.asp?id=34

Le site du Frederick K Cox International Law Center War Crimes Research Portal présente quatre avantages. Il contient ainsi une liste de plus de 1000 hyperliens associés au droit humanitaire international, présentés par ordre alphabétique et par thème avec un résumé pour chaque site. Il inclut le texte de mémoranda de recherche sur les cas présentés dans les différentes cours internationales, selon la date de publication, le titre ou les mots clés. Il présente un guide de recherche sur la question du droit humanitaire international, une bibliographie d'articles et de livres ainsi que des hyperliens aux journaux de droit. Le portail contient aussi des articles mensuels sur le droit criminel international.

www.truthcommission. org/about.php?lang=fr

Ce site sur les commissions vérité a pour objectif de présenter la littérature sur les commissions vérité de façon concise afin d'aider les personnes intéressées à créer ce type de structure. Ce site interactif propose des informations plus complètes sur les commissions les plus performantes (argentine, chilienne, salvadorienne, guatémaltèque et sud-africaine), ce qui permet de mieux comprendre l'originalité et les contraintes associées à ce type d'organisation.

\section{GÉNOCIDES}

\section{http://migs.concordia.ca/}

Le Montreal Institute for Genocide and Human Rights Studies (MIGS) est localisé à l'Université Concordia. Fondé en 1986 par les professeurs Franck Chalk et Kurt Jonassohn, il s'inscrit dans une perspective historique et comparative, et ce, en collaboration avec des chercheurs provenant de divers horizons disciplinaires et nationaux. Il développe des recherches sur les génocides, organise des ateliers, des conférences et des cours et publie des travaux sur ces questions. À travers le site, il est possible d'accéder à des informations sur les activités et les publications en ligne des différents chercheurs.

\section{http://www.cybercambodia.com/dachs/index.html}

Ce site est dédié à la mémoire des victimes du génocide cambodgien et aux survivants. Il propose des archives photographiques, des documents sur ce génocide ainsi que des témoignages de survivants.

\section{http://www.preventgenocide.org/}

Le site Prevent Genocide International, établi en 1998, est un réseau d'éducation et d'action pour la prévention des génocides et des crimes contre l'humanité. Il propose des documents sur la définition des génocides dans le champ des sciences sociales et du droit international. Les éléments impliqués dans le crime de génocide, les modalités de sanction, des témoignages de survivants et des textes de Raphael Lemkin sur le génocide sont présentés. http://www.armeniapedia.org/index.

php?title=Armenian_Genocide

Ce site porte sur le génocide arménien et fait la revue des évènements qui sont menés. Il analyse son déroulement, la cartographie des massacres et des trajets de déportation, de même que ses répercussions locales et nationales. De nombreux hyperliens sont proposés.

\section{http://www.ppu.org.uk/genocide/}

Ce site présente des informations sur la définition du génocide, un historique des différents génocides survenus dans l'histoire (Namibie, Arménie, Ukraine, Holocauste, Cambodge, Guatémala, Rwanda et Bosnie), de même que des témoignages de survivants et des articles de référence sur ce thème.

http://www.yadvashem.org/

Ce site fournit des informations sur le Yad Vashem, le centre israélien sur la Shoah localisé à Jérusalem. Il propose une banque de données sur les victimes, une visite virtuelle de son musée, de même que des ressources éducatives en plusieurs langues et un matériel considérable en ligne (articles, photographies, documents, cartes, collections d'objets et œuvres d'art, expositions).

\section{PEINE DE MORT}

http://www.peinedemort.org/peinedemort.php

Le site Peine de mort présente les grandes lignes de l'actualité internationale sur cette question, présente les enjeux au plan international et national français (textes fondateurs, institutions gouvernementales et non gouvernementales, fiche par pays). Il fournit un bulletin d'information sur la peine de mort et établit des liens avec d'autres sites Internet.

\section{http://efai.amnesty.org/}

Le site d'Amnistie internationale, un des organismes non gouvernementaux les plus connus dans le domaine des droits de l'homme, ainsi que plusieurs sous-thèmes touchant la question de la politique et de la mort. Amnistie internationale, il mène des campagnes, entre autres contre la violence envers les femmes, la torture, la peine de mort et pour le contrôle des armes. L'outil de recherche permet de consulter de nombreux documents touchant les questions de la protection des individus. Ainsi, sur la peine de mort, il est possible d'accéder à un Bulletin sur la peine de mort, aux rapports sur cette question, les traités internationaux et la situation dans les différents pays. Des liens à de nombreux sites complémentaires sont aussi fournis.

http://www.worldcoalition.org

Le site Coalition mondiale contre la peine de mort, créé en 2002, regroupe un ensemble d'organisations non gouvernementales, des associations de juristes, des syndicats et des institutions prônant l'abolition de la peine de mort. Cette coalition participe et organise des actions sur le plan international. Le site présente l'historique de la Coalition, les actions qu'elle mène et de l'information sur les journées mondiales. 